\title{
ENSAIOS
}

\section{PRÁTICAS CORPORAIS QUILOMBOLAS: UM ESTUDO DA PRODUÇÃO ACADÊMICA NA EDUCAÇÃO FÍSICA}

\author{
QUILOMBOLA BODILY PRACTICES: A STUDY OF ACADEMIC \\ PRODUCTION IN PHYSICAL EDUCATION C्.
}

PRÁCTICAS CORPORALES QUILOMBOLAS: UN ESTUDIO DE LA PRODUCCIÓN ACADÉMICA EN LA EDUCACIÓN FÍSICA C己

doi' $\mathrm{https://doi.org/10.22456/1982-8918.111523}$

(D) Paulino Pinheiro Gaia* <paulinogaia@hotmail.com>

(D) Ingrid Dittrich Wiggers* <ingridwiggers@gmail.com>

(D) Layana Costa Ribeiro Cardoso* <layanacardoso@gmail.com>

(D) Maria Denise Dourado da Silva*<mdedourado@gmail.com>

(D) Dulce Maria Filgueira de Almeida* < dulce.filgueira@gmail.com>

*Universidade de Brasília (UnB). Brasília, DF, Brasil.

Resumo: $\mathrm{O}$ artigo analisa o sentido/significado das práticas corporais quilombolas na produção acadêmica, identificando sua distribuição por áreas de conhecimento e seu mapeamento geoespacial no Brasil. Uma pesquisa de natureza teórica e bibliográfica foi realizada em bases de dados, no período compreendido entre 1999 e 2019. Os resultados apontam que o sentido/significado das práticas corporais está associado às representações sociais sobre a cultura corporal de movimento, evidenciando que a Educação Física e a Educação se destacam entre as áreas de conhecimento e os estudos se distribuem geoespacialmente no Brasil. Os loci das pesquisas estão, predominantemente, na Região Nordeste; a Universidade de Brasília e a Universidade Federal do Ceará despontam em números de trabalhos. Conclui-se que, apesar de recente e pouco estudada, a relevância da temática estimula uma agenda de pesquisa.

Palavras chave: Exercício físico. Grupo com ancestrais do continente africano. Indicadores de produção científica. Educação Física.

Recebido em: 19 fev. 2021 Aprovado em: 13 ago. 2021 Publicado em: 20 set. 2021

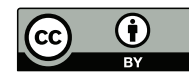

Este é um artigo publicado sob a licença Creative Commons Atribuição 4.0 Internacional (CC BY 4.0).

eISSN: $1982-8918$ 


\section{INTRODUÇÃO}

O Relatório Nacional de Desenvolvimento Humano no Brasil, produzido pelo Programa das Nações Unidas (PNUD, 2017), apresenta um conjunto de temas que foram objeto de preocupação e de debates travados pela comunidade acadêmica da Educação Física, numa abordagem sociocultural. Um dos fios condutores do relatório era tratar das atividades físicas e esportivas, que, no escopo das relações mediadas por populações tradicionais, foram definidas como práticas corporais. As populações tradicionais foram tratadas sob três recortes: indígenas, ribeirinhas e quilombolas, sobre os quais nos deteremos aqui (ALMEIDA et al., 2017).

Os primeiros quilombos no Brasil surgiram como forma de resistência ao regime escravista, que se iniciou por volta de $1570 \mathrm{com}$ a chegada dos primeiros africanos vindos de diversos países daquele continente (FAUSTO, 2006). Enquanto conceito, ao que parece, o termo quilombo foi utilizado pela primeira vez no Conselho Ultramarino em 1740 em resposta ao Rei de Portugal. A definição se prendia a aspectos que se reportavam à aglomeração ou localização geográfica. De acordo com Schmitt, Turatti e Carvalho (2002, p. 2), trata-se de toda a sorte de "[...] habitação de negros fugidos que passem de cinco, em parte despovoada, ainda que não tenham ranchos levantados e nem se acham pilões neles".

No que concerne às práticas corporais de povos remanescentes de quilombos, também chamados de populações quilombolas, a presença dos estudos decorre das duas últimas décadas. Isto porque, apesar do registro na Constituição Federal de 1988, em seu Art. 215, de uma agenda propositiva destinada aos povos remanescentes de quilombos, estes só vão existir, de fato, a partir de 2004, com o "Programa Brasil Quilombola" da Secretaria de Políticas de Promoção da Igualdade Racial (SEPPIR). A chamada "Agenda Social Quilombola" apresentava os seguintes eixos: acesso à terra; infraestrutura e qualidade de vida; inclusão produtiva e desenvolvimento local; e direitos e cidadania (ALMEIDA et al., 2017).

Igualmente, os estudos e pesquisas na área da Educação Física sobre populações quilombolas se localizam neste período (LIMA; BRASILEIRO, 2020). Acredita-se que o desenvolvimento dessas pesquisas desde então se deu em decorrência do aumento do número de programas de pós-graduação no Brasil, com um certo esforço de interiorização destes, visto que, em alguns estados, a exemplo de Goiás e do Paraná, entre outros, bem como no Distrito Federal, havia um número significativo de populações quilombolas localizadas em seus respectivos territórios.

Debater sobre as práticas corporais quilombolas é uma forma de chegar à dimensão social das expressões, manifestações e significados corporais, possibilitando a consolidação de um novo entendimento nessa conjuntura social. As práticas corporais quilombolas, dentro do campo de movimento e de produção cultural, são formas legítimas de manifestação da comunidade, de resistência, de valorização étnica, de luta política, e não podem ser camufladas ou sufocadas por outras políticas ou práticas hegemônicas (SOUZA; LARA, 2011).

Considerando os aspectos acima destacados, o artigo tem como objetivo analisar o sentido/significado das práticas corporais quilombolas no âmbito da 
produção acadêmica, bem como identificar sua distribuição por áreas de conhecimento e seu mapeamento geoespacial. Esperamos contribuir para o delineamento de uma agenda de pesquisa, levando em conta as tendências dos primeiros anos da produção acadêmica em torno da temática no Brasil.

\section{METODOLOGIA}

A pesquisa, de natureza teórica, apresenta-se como bibliográfica, sendo realizada com base na produção acadêmica sobre práticas corporais quilombolas e seu impacto em termos de área de conhecimento, bem como de distribuição geoespacial. Consoante Flick (2009), a pesquisa bibliográfica pode ser feita em diferentes materiais, desde a consulta a periódicos, teses, dissertações, livros e até anais de eventos científicos. Esse conjunto de trabalhos acadêmicos é considerado tradicionalmente como fontes primárias de pesquisas, apontando lacunas e tendências de um tema. Atualmente, observa-se em abordagens qualitativas a sistematização da análise de fontes bibliográficas, o que pode gerar sínteses interpretativas e criativas (RAPLEY; REES, 2018). Desse modo, a revisão sistemática da literatura científica transpassa a simples organização e resumo dos achados de pesquisas, produzindo novas categorias e até mesmo modelos conceituais e teorias, que se tornam uma base sólida para realização de investigações futuras.

A abordagem desta pesquisa, tendo-se como recorte temporal o período compreendido entre 1999 e 2019, foi realizar consulta nas seguintes bases de dados: Web of Science ; Scopus ; e Base de Dados de Teses e Dissertações (BDTD) do Instituto Brasileiro de Informação em Ciência e Tecnologia (IBICT) . A busca concentrou-se em teses, dissertações e artigos científicos produzidos acerca das populações quilombolas, com vistas à análise de sentidos/significados das práticas corporais. A produção das informações foi organizada em três fases, conforme demonstrado na Figura 1.

Figura 1 - Processo metodológico - produção das informações e análise dos trabalhos.

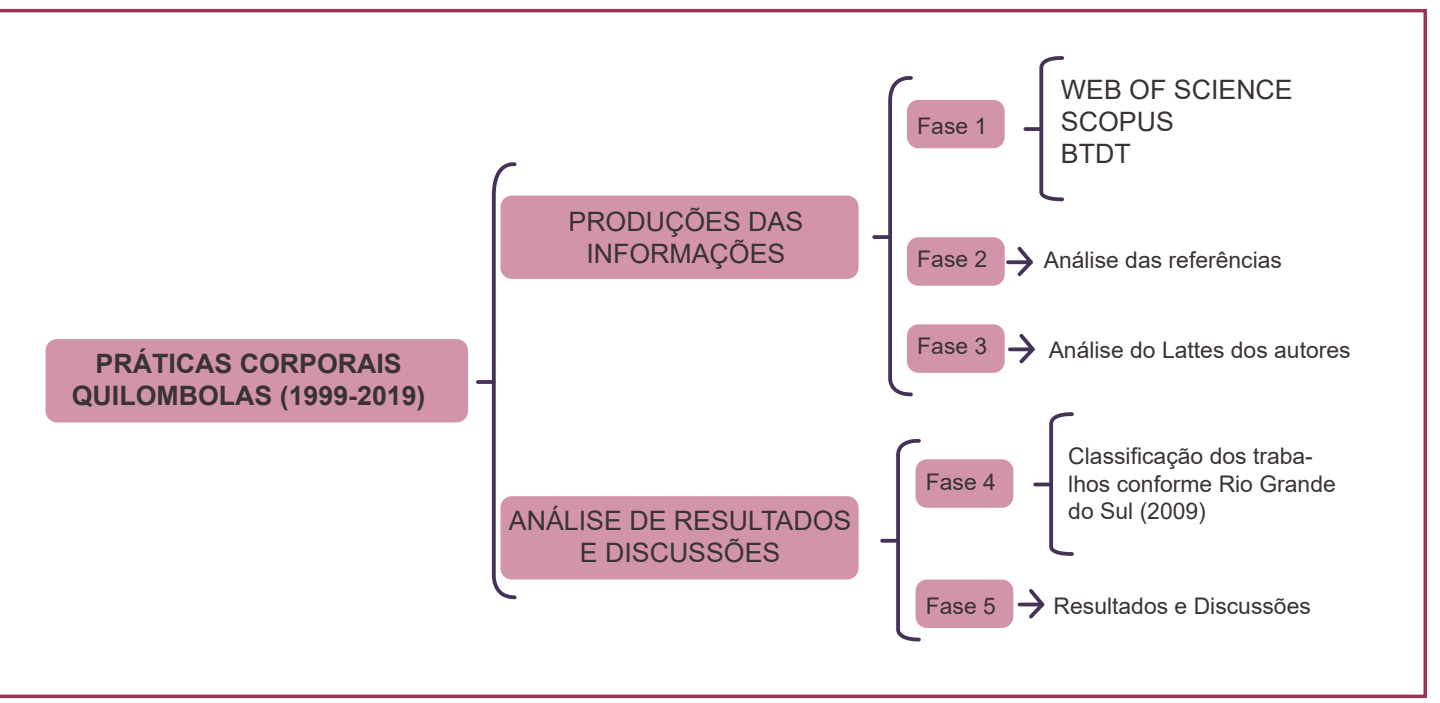

Fonte: elaborado pelos autores, 2020. 
Para a consecução da primeira fase, o acesso deu-se por meio do portal de periódicos da Capes". No espaço de busca, clicou-se em "BASE" e depois digitou-se "Web of Science" ou "Scopus" para acessar as referidas bases. Já com a BDTD² utilizaram-se diretamente os descritores no espaço de busca. Os descritores utilizados foram "pratica* corporal " OR "corporal practice*" OR "body" practice *" OR dança* OR dance* OR esporte* OR sport* OR lazer* OR leisure* AND quilombola* OR quilombo*, empregando-se o operador booleano "AND" para restringir a pesquisa, fazendo a intersecção dos conjuntos de trabalhos que possuem os termos combinados, as "aspas" para definir a exatidão da palavra a ser pesquisada, além de inserir o asterisco $\left(^{*}\right)$ no final do radical para ampliar possibilidades de resultados.

A inclusão dos artigos, dissertações e teses deu-se, inicialmente, a partir da leitura dos títulos, resumos e palavras-chave, para definir quais realmente tratavam do tema de interesse da pesquisa. Como fator de exclusão, lidou-se com o fato de o trabalho não abordar a temática "práticas corporais quilombolas". Os achados da pesquisa somam 91 produtos, dos quais apenas 33 enfocam especificamente o assunto, conforme a Tabela 1.

Tabela 1 - Número de trabalhos relacionados à temática práticas corporais quilombolas, no período entre 1999-2019, conforme a base de dados.

\begin{tabular}{ccc}
\hline Bases & Total & Número de trabalhos relacionados à temática \\
\hline 1. Web of Science & 4 & 4 Artigos \\
\hline 2. Scopus & 16 & \\
\hline 3. BDTD & 71 & (8 Teses + 21 Dissertações) $=29$ \\
\hline TOTAL & 91 & 33 \\
\hline & Fonte: elaborada pelos autores, 2020.
\end{tabular}

$\mathrm{Na}$ base de dados Web of Science obtivemos quatro artigos, sendo somente um relacionado à temática práticas corporais quilombolas. Já na base da Scopus apareceram dezesseis artigos. Dentre estes, quatro apresentam aderência ao tema de interesse. Ressalvamos que o único exemplar localizado na base Web of Science também foi encontrado na base da Scopus. Por este motivo mesclamos o campo "número de trabalhos relacionados à temática" das bases Web of Science e Scopus, evitando duplicidade. Tratando-se da BTDT tivemos um resultado mais significativo, pois foram localizados 71 produtos no total. No entanto, apenas 29 deles, sendo oito teses e 21 dissertações, estão inseridos dentro do tema específico.

Diante da expectativa de selecionar um número maior de fontes, a produção das informações abrangeu outras fases, por meio da análise das referências bibliográficas dos artigos, bem como dos respectivos currículos Lattes dos autores das teses e dissertações. Conforme as orientações de Luna (1997), as referências citadas em trabalhos científicos podem servir como fonte de dados, pois auxiliam o pesquisador a encontrar mais fontes adequadas ao seu problema. Desse modo,

1 Disponível em: $\underline{w w w}$.periodicos.capes.gov.br

2 Disponível em: www.bdtd.ibict.brwww.bdtd.ibict.br 
identificamos um total de 35 produtos gerados a partir das teses e dissertações sobre a temática, conforme apresentado na Tabela 2.

Tabela 2 - Número de produtos gerados a partir de teses e dissertações sobre a temática, de acordo com o tipo.

\begin{tabular}{ccccc}
\hline $\begin{array}{c}\text { Trabalho/ } \\
\text { Estudo }\end{array}$ & $\begin{array}{c}\text { Número de } \\
\text { dissertações } \\
\text { e teses }\end{array}$ & $\begin{array}{c}\text { Número de } \\
\text { produtos } \\
\text { gerados }\end{array}$ & Tipo & $\begin{array}{c}\text { Número de } \\
\text { produtos gerados, } \\
\text { por tipo }\end{array}$ \\
\hline \multirow{2}{*}{ Dissertação } & 21 & 21 & Artigo & 8 \\
& & & Capítulo de livro & 6 \\
Tese & 8 & 14 & Livro & 7 \\
\hline Total & 29 & Capítulo de livro & 7 \\
\hline
\end{tabular}

Fonte: elaborada pelos autores, 2020.

Observamos que as teses geraram 14 produtos, enquanto outros 21 se desdobraram das dissertações. Entre artigos, capítulos de livro e livros, proporcionalmente, obtivemos em média, aproximadamente, dois produtos por tese e um por dissertação. Esta produção localizada por fora das bases de dados indica a necessidade de se disponibilizá-la em vias que repercutem os seus resultados na comunidade científica, dando maior abrangência ao tema. Salientamos que a consolidação de um campo depende da produção de artigos científicos advindos das teses e dissertações defendidas, com vistas à socialização do conhecimento e consequente impacto na sociedade (RAMOS et al., 2009).

Após a produção das informações, desenvolvemos a análise de resultados, visando a uma discussão qualitativa dos trabalhos, conforme representado na Figura 1. Priorizamos os trabalhos selecionados por meio das bases de dados, pois aqueles encontrados nas fases complementares do processo metodológico se referem a produtos gerados a partir dos trabalhos encontrados na primeira etapa. O conteúdo dos produtos gerados a partir das teses e dissertações, por conseguinte, se encontra nos trabalhos originais, o que dispensa a sua consideração no processo de análise de cunho qualitativo.

Diante do resultado obtido na consulta às bases, os 33 trabalhos foram inicialmente identificados conforme o título, o tipo e o ano de produção. Em seguida, a análise empreendida observou critérios de abordagem de documentos propostos por Coffey (2014), como a orientação teórico-metodológica e os resultados evidenciados nos trabalhos. Na continuidade, nos valemos da categorização do Referenciais Curriculares do Estado do Rio Grande do Sul (RIO GRANDE DO SUL, 2009), visando a uma compreensão dos sentidos/significados das práticas corporais quilombolas do âmbito da produção acadêmica. 


\section{A PRODUÇÃO SOBRE PRÁTICAS CORPORAIS QUILOMBOLAS}

As práticas corporais podem ser entendidas como construções socioculturais de cada grupo social, ao tempo em que expressam sentidos e significados próprios e materializam a memória e a consciência coletivas do grupo, nomeadamente de populações tradicionais, como comunidades indígenas, ribeirinhas e quilombolas (ALMEIDA et al., 2017). São práticas que têm como referência e são transmitidas por meio de um conjunto de técnicas corporais, empregando-se a tradição oral e a eficácia simbólica, igualmente definida como imitação prestigiosa no âmbito da disciplina antropológica (MAUSS, 2017).

Para a análise da produção selecionada, notadamente, considerando o sentido/ significado das práticas corporais quilombolas, operamos com a categorização dos Referenciais Curriculares do Estado (RIO GRANDE DO SUL, 2009). Esta, por sua vez, foi adaptada de acordo com a aderência das produções selecionadas às categorias, consoante a Figura 2. Desse modo, evidenciou-se que a produção sobre práticas corporais quilombolas, no período compreendido entre 1999 e 2019, se concentra no conjunto "Representações sociais sobre a cultura corporal de movimento". No âmbito deste conjunto, por sua vez, foi privilegiada a categoria "Práticas corporais e sociedade" e especificamente a subcategoria "Práticas corporais como manifestações culturais".

Figura 2 - Categorização das práticas corporais quilombolas

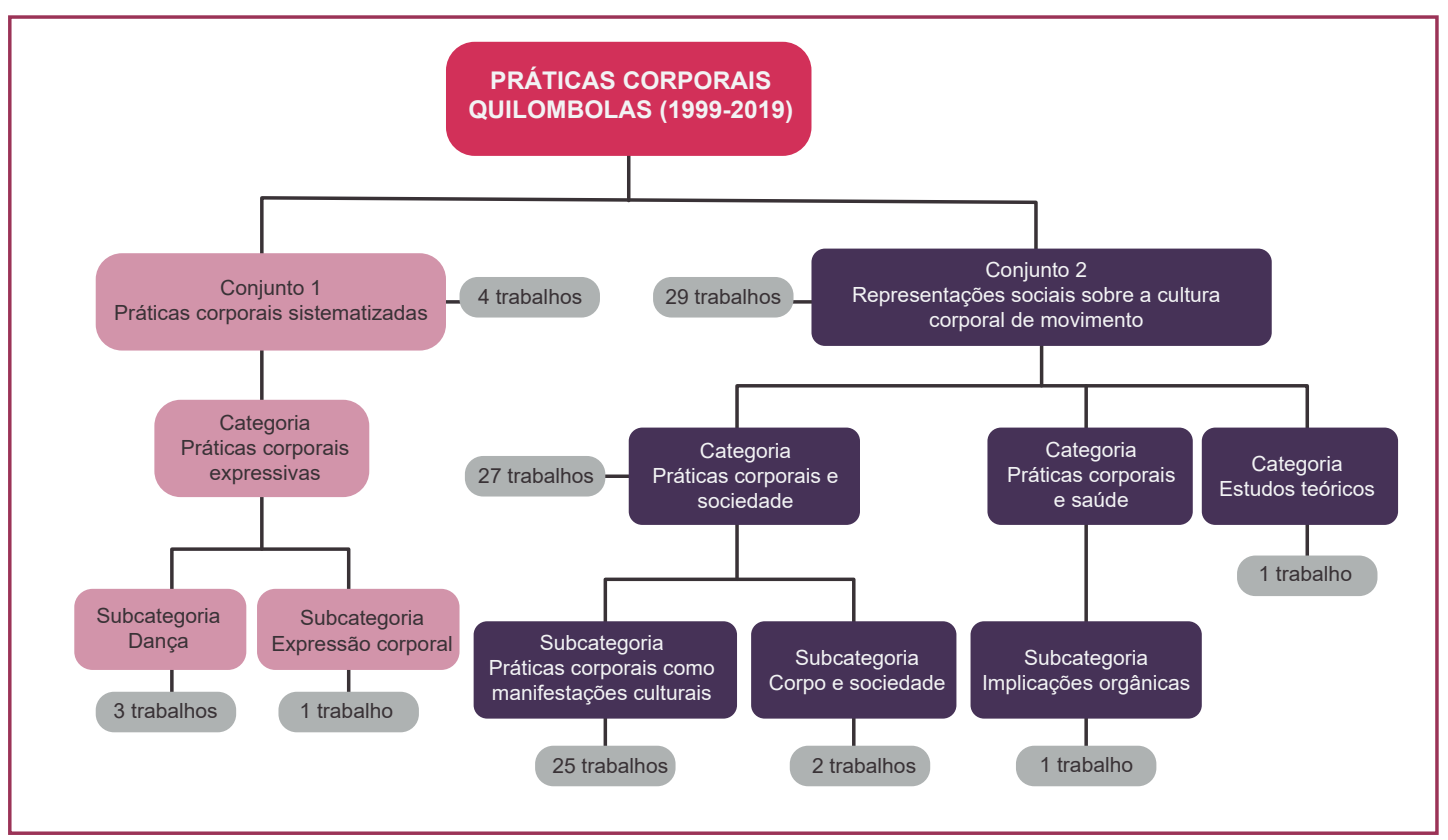

Fonte: Adaptado de Referenciais Curriculares (RIO GRANDE DO SUL, 2009, p. 119).

Em consonância às categorias dos Referenciais Curriculares (RIO GRANDE DO SUL, 2009), do total de 33 produções analisadas, verifica-se que 27 trabalhos, o que representa $82 \%$, estão localizados na categoria "Práticas corporais e sociedade". Apesar desta clara concentração, não se poderia deixar de observar que outras categorias também foram abordadas, embora em número reduzido de pesquisas (Gráfico 1). 
Gráfico 1 - Produções das práticas corporais quilombolas (1999-2019) conforme Referenciais Curriculares do Rio Grande do Sul (2009).

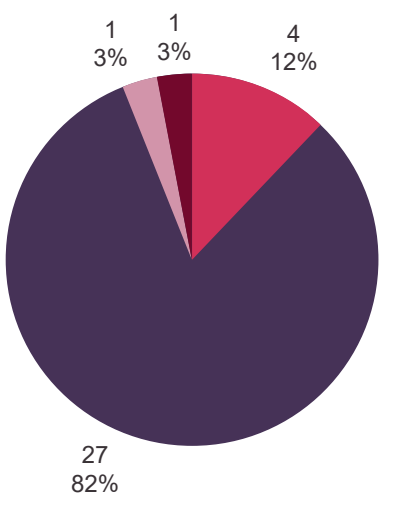

Práticas Corporais Expressivas

Práticas Corporais e Sociedade

Práticas Corporais e Saúde

Categoria Estudos Teóricos

Fonte: elaborado pelos autores, 2020

A categoria "Práticas corporais e sociedade" reúne trabalhos que abordam objetos de estudo que se referem às subcategorias "Práticas corporais como manifestações culturais" e "Corpo e sociedade". Ressalvamos que, de acordo com os Referencias Curriculares do Rio Grande do Sul (RIO GRANDE DO SUL, 2009), o trato das representações sociais da cultura corporal de movimento diz respeito às manifestações corporais mais amplas e não estão relacionadas, de modo direto, ao campo da Educação Física. No tocante à maior parte dos achados da pesquisa, ou seja, 27 trabalhos, foram identificadas 19 dissertações, sete teses e um artigo, conforme o Quadro 1.

Quadro 1 - Produções na categoria práticas corporais e sociedade, em ordem cronológica crescente e de acordo com o tipo.

\begin{tabular}{|c|c|c|c|}
\hline $\mathbf{N}^{\mathbf{0}}$ & Título & Ano & Tipo \\
\hline 1 & "Tá ligado mano": o hip-hop como lazer e busca da cidadania & 2005 & Tese \\
\hline 2 & $\begin{array}{c}\text { As artes e as técnicas do ser e do saber/fazer em algumas atividades } \\
\text { no cotidiano da comunidade kalunga do riachão }\end{array}$ & 2007 & Dissertação \\
\hline 3 & $\begin{array}{c}\text { O zambê é nossa cultura: o coco de zambê e a emergência ética em } \\
\text { Sibaúma, Tibau do Sul-RN. }\end{array}$ & 2009 & Dissertação \\
\hline 4 & $\begin{array}{c}\text { Batuques, folias e ladainhas: a cultura do quilombo do Cria-ú em } \\
\text { Macapá e sua educação }\end{array}$ & 2010 & Tese \\
\hline 5 & $\begin{array}{c}\text { Entre gingas e cantigas: etnografia da performance do ensaio de } \\
\text { promessa de quicumbi entre os morenos de Tavares, Rio Grande do Sul. }\end{array}$ & 2010 & Dissertação \\
\hline 6 & $\begin{array}{c}\text { Brincadeira e arte: patrimônio, formação cultural e samba de coco em } \\
\text { Pernambuco }\end{array}$ & 2011 & Tese \\
\hline 7 & $\begin{array}{c}\text { As representaçães sociais das práticas corporais na comunidade } \\
\text { Kalunga-Go }\end{array}$ & 2011 & Dissertação \\
\hline 8 & Dança do Congo: educação, expressão, identidade e territorialidade & 2011 & Dissertação \\
\hline 9 & $\begin{array}{c}\text { Memórias das danças do marabaixo e do batuque: cultura quilombola e } \\
\text { corporeidade na comunidade do Curiaú em Macapá-AP }\end{array}$ & 2012 & Dissertação \\
\hline 10 & $\begin{array}{c}\text { Jongo e educação: a construção de uma identidade quilombola a partir } \\
\text { de saberes étnico-culturais do corpo }\end{array}$ & 2013 & Tese \\
\hline 11 & $\begin{array}{r}\text { Os ritmos tradicionais nos tambores do Tocantins: constituições } \\
\text { identitárias e processos culturais }\end{array}$ & 2013 & Dissertação \\
\hline 12 & $\begin{array}{r}\text { O processo ritual nas festas da comunidade Kalunga de Teresina de } \\
\text { Golás }\end{array}$ & 2013 & Dissertação \\
\hline
\end{tabular}


Continuação do quadro 1.

\begin{tabular}{|c|c|c|c|}
\hline 13 & $\begin{array}{c}\text { Os quilombolas do Veiga e o São Gonçalo: memória e identidade na } \\
\text { festa e devoção a São Gonçalo no Sítio Veiga }\end{array}$ & 2014 & Dissertação \\
\hline 14 & $\begin{array}{l}\text { Brincando de sair pra rua! Entre arreganhos, implicâncias e cuidados no } \\
\text { "pátio" do quilombo, na "piscina" do laguinho. }\end{array}$ & 2014 & Dissertação \\
\hline 15 & $\begin{array}{l}\text { Práticas corporais nas comunidades quilombolas: significados das } \\
\text { manifestações culturais na escola de Monte Alegre }\end{array}$ & 2014 & Dissertação \\
\hline 16 & $\begin{array}{l}\text { Corpos no samba de cacete: dança ancestral, tambores giras e gingas } \\
\text { na educação afrocametaense }\end{array}$ & 2015 & Dissertação \\
\hline 17 & $\begin{array}{l}\text { Domínios de atividade física em comunidades quilombolas do sudoeste } \\
\text { da Bahia, Brasil: estudo de base populacional }\end{array}$ & 2015 & Artigo \\
\hline 18 & $\begin{array}{c}\text { Campo de mandinga: presentificação estética, ética e política na } \\
\text { capoeira Angola }\end{array}$ & 2016 & Tese \\
\hline 19 & $\begin{array}{l}\text { Narradoras do batuque: protagonismo e identidade no quilombo do } \\
\text { Serrote }\end{array}$ & 2017 & Dissertação \\
\hline 20 & $\begin{array}{l}\text { Coco de roda novo quilombo: da roda ao centro, imagens e símbolos de } \\
\text { uma tradição }\end{array}$ & 2017 & Dissertação \\
\hline 21 & Sítio alto: entre dança, história e etnicidade & 2017 & Dissertação \\
\hline 22 & $\begin{array}{c}\text { Vem que hoje é dia de festa: Corpo, território e ancestralidade nas } \\
\text { festas da Comunidade Quilombola Carrapatos da Tabatinga - Bom } \\
\text { Despacho, MG }\end{array}$ & 2017 & Tese \\
\hline 23 & $\begin{array}{c}\text { Terça negra no Recife: Narrativas sobre dança, música, espiritualidade } \\
\text { e sagrado }\end{array}$ & 2018 & Dissertação \\
\hline 24 & $\begin{array}{c}\text { Comunicação e identidades: um estudo sobre as práticas culturais da } \\
\text { comunidade quilombola de capoeiras no Rio Grande do Norte }\end{array}$ & 2018 & Dissertação \\
\hline 25 & $\begin{array}{c}\text { Os Capotês de São Benedito em Montes Claros: Rastros de uma } \\
\text { ancestralidade mineira negra e festiva }\end{array}$ & 2018 & Dissertação \\
\hline 26 & $\begin{array}{l}\text { Mulheres negras: religiosidade, atividades artístico-culturais, } \\
\text { consciência }\end{array}$ & 2018 & Dissertação \\
\hline 27 & $\begin{array}{l}\text { Entre o rio e o mar: práticas corporais e cotidiano na comunidade } \\
\text { quilombola do Cumbe }\end{array}$ & 2018 & Tese \\
\hline
\end{tabular}

Fonte: elaborado pelos Autores, 2020.

Ante ao que se observa, com base na descrição dos estudos acima, 25 trabalhos estão relacionados à subcategoria "Práticas corporais como manifestações culturais". A dança, por sua vez, se apresenta como temática central desta categoria de pesquisas. Grosso modo, os referidos estudos descrevem que as comunidades quilombolas, por meio da dança, reivindicam melhorias para sua comunidade. Os vieses analíticos, portanto, remetem aos processos identitários dos grupos sociais por meio e com a dança. Santos (2011), por exemplo, enfoca a perspectiva das representações sociais, por meio de práticas corporais com dança em comunidades quilombolas no estado do Goiás. Em concordância, pesquisas realizadas por Oliveira (2018) visam compreender os sentidos e significados das práticas corporais expressas no cotidiano de um grupo social quilombola, tendo as práticas corporais como mecanismos de resistência cultural do corpo pesqueiro-quilombola no âmbito do ritual "Cumê no Mato" e do teatro dos Calungas do Cumbe. Ainda de acordo com os achados da pesquisa, o espetáculo artístico e a riqueza das técnicas dos movimentos gestuais apresentam o êxtase da dança como comunicação do corpo expressivo. Aqui se encontram trabalhos que versam sobre a Dança de São Gonçalo (MORENO, 2014); Zumba de Coco (LINS, 2009); Samba de Cacete (CALÚ, 2015); Coco de Roda (BARRETO, 2017); Jongo (MAROUN, 2013), entre outras. 
$\mathrm{Na}$ outra subcategoria "Corpo e sociedade", que integra a categoria "Práticas corporais e sociedade", foram identificados apenas um artigo e uma dissertação. Ambos procuram entender os significados sociais atribuídos ao corpo durante as distintas fases da vida, conhecendo os padrões de beleza que marcaram época, bem como as produções de aceitação dos grupos sociais próximos e distantes de onde se vive, além de identificar e analisar o corpo no trabalho. Aqui buscamos aproximação ao corpo, nos apoiando na compreensão de Mauss (2017, p. 425), quando nos alerta que "[...] não se podia ter uma noção clara de todos esses fatos, senão fazendo intervir uma tríplice consideração, com a qual a concepção de fato social total se faz indispensável".

Nesse desígnio, o estudo de Bezerra et al. (2015) descreve as prevalências e os fatores associados à atividade física nos domínios do lazer, trabalho e deslocamento entre quilombolas. Enquanto Pereira (2014) nos apresenta as relações de dois grupos de crianças e adolescentes que estão utilizando a rua como um espaço de lazer e sociabilidade em dois locais diferentes da cidade de Porto Alegre/RS. Um grupo está longe de casa e diverte-se em um lago artificial próximo ao centro da cidade. O outro reside em um quilombo urbano e tem a rua como extensão de sua casa, um pátio. Podemos interpretar que, em ambos os trabalhos, a saber, Bezerra et al. (2015) e Pereira (2014), as experiências dos distintos grupos no mundo da rua e/ou no mundo do trabalho e suas compreensões sobre as sociabilidades se configuram como o fio condutor das análises empreendidas pelos autores acerca do significado das práticas corporais. Tais compreensões aliam-se, portanto, ao que já afirmavam Le Breton (2006) e Mauss (2017) acerca do corpo e de suas possíveis mediações. Para ambos, o corpo e o conjunto de suas técnicas expressam significações socioculturais.

A categoria "Práticas corporais expressivas" se caracteriza pela abordagem de temáticas que se referem às subcategorias "Dança" e "Expressão corporal". Foram identificadas quatro produções que se situam nesta categoria, sendo duas dissertações e um artigo, conforme o Quadro 2.

Quadro 2 - Produções na categoria práticas corporais expressivas, em ordem cronológica crescente e de acordo com o tipo.

\begin{tabular}{|c|c|c|c|}
\hline $\mathbf{N}^{\circ}$ & Título & Ano & Tipo \\
\hline 1 & $\begin{array}{c}\text { A construção de uma identidade quilombola a partir da prática } \\
\text { corporal/cultural do Jongo }\end{array}$ & 2014 & Artigo \\
\hline 2 & $\begin{array}{c}\text { O ensino do teatro em comunidades negras rurais: memórias e } \\
\text { identidades Kalunga em cena }\end{array}$ & 2015 & Dissertação \\
\hline 3 & $\begin{array}{c}\text { A gira de saberes no processo de criação de estella: manifesto por } \\
\text { uma dança afropoética }\end{array}$ & 2018 & Dissertação \\
\hline 4 & $\begin{array}{c}\text { Análise das práticas pedagógicas o processo educativo do Jongo } \\
\text { no quilombo machadinha: oralidade, saber da } \\
\text { experiência e identidade }\end{array}$ & 2019 & Artigo \\
\hline
\end{tabular}

Fonte: elaborado pelos autores, 2020

Segundo os dados, verifica-se pelo título dos trabalhos que, assim como nos trabalhos pertencentes à primeira categoria analisada, há um predomínio da temática dança. Os achados que contemplam as subcategorias "Dança e expressão corporal" relatam, de acordo com Maroun (2014), que as vivências de práticas 
realizadas por meio de danças populares são, em sua maioria, ligadas a festividades religiosas, como o Jongo. Já Costa (2015) apresenta experiências teatrais, por meio das possibilidades expressivas do corpo ligadas intrinsecamente às memórias e às identidades do grupo social.

Com base na análise de outros elementos das pesquisas, como a leitura de resumos e dos textos propriamente ditos, pode-se afirmar que estas investigações atendem a um viés de intervenção. Isto é, elas se propõem a realizar vivências de práticas corporais específicas. A dissertação pertencente a esta subcategoria, por exemplo, exibiu em seus objetivos descrever o processo de criação de uma dança, que entrelaça o intento de falar de gente, dor, revolta e alegria guerreira em reverência à ancestralidade africano-brasileira, no qual se descreve o corpo a ritualizar gestos cotidianos de escavar, tecer, tramar, recriar memórias, histórias, conflitos e sensações (SILVA, 2018). Assim, a concepção de corpo se relaciona diretamente àquela sugerida por Mauss (2017, p. 432), que dispõe de "[...] técnicas que lhe dizem respeito ou que Ihe ensinam". Os artigos convergem quanto aos objetivos, apresentando em estudos realizados por Costa e Fonseca (2019) vivências no processo de construção de uma identidade quilombola a partir da prática corporal/cultural do Jongo. O processo educativo da dança é abordado, tendo essa manifestação como uma prática afroancestral, característica dos quilombos pesquisados.

No tocante à categoria "Práticas corporais e saúde", identificou-se apenas um trabalho, que se refere, por sua vez, à subcategoria "Implicações orgânicas". De acordo com os Referenciais Curriculares do Estado (RIO GRANDE DO SUL, 2009), esta subcategoria busca diferenciar conceitos de atividades físicas e exercício físico, bem como entender e observar os cuidados relacionados à alimentação e hidratação, compreendendo a saúde e a doença como processos indissociáveis de fatores sociais, orgânicos, culturais e econômicos. De acordo com o Quadro 3, foi encontrada uma tese com este perfil.

Quadro 3 - Produção na categoria práticas corporais e saúde, de acordo com o tipo.

\begin{tabular}{|c|c|c|c|}
\hline $\mathbf{N}^{\circ}$ & Título & Ano & Tipo \\
\hline 1 & $\begin{array}{c}\text { Territorialidade, saúde e meio ambiente: conexões, saberes e práticas } \\
\text { em comunidades quilombolas de Sergipe }\end{array}$ & 2017 & Tese \\
\hline
\end{tabular}

Fonte: elaborado pelos autores, 2020.

Sob o título "Territorialidade, saúde e meio ambiente: conexões, saberes e práticas em comunidades quilombolas de Sergipe", a tese objetiva "analisar como os saberes e práticas tradicionais de cuidado em saúde constroem territorialidades que contribuem para conservação ambiental em comunidades quilombolas" (LACERDA, 2017, p. 9). Apresenta os saberes e práticas que articulam saúde e meio ambiente, destacando a utilização de plantas medicinais, as práticas de reza e benzedura, a conservação de sementes crioulas e as danças circulares samba de coco e dança de roda.

Quanto à categoria "Estudos teóricos", foi encontrado no conjunto da produção analisada apenas um artigo, apresentado no Quadro 4: 
Quadro 4 - Produções na categoria estudos teóricos, de acordo com o tipo.

\begin{tabular}{|c|c|c|c|}
\hline $\mathbf{N}^{\circ}$ & Título & Ano & Tipo \\
\hline 1 & $\begin{array}{c}\text { O estado da arte de comunidades quilombolas no Paraná: produção de } \\
\text { conhecimento e práticas corporais recorrentes }\end{array}$ & 2011 & Artigo \\
\hline
\end{tabular}

Fonte: elaborado pelos autores, 2020.

Com efeito, o trabalho acima identificado trata de apresentar "O estado da arte de comunidades quilombolas no Paraná: produção de conhecimento e práticas corporais recorrentes". De autoria coletiva, realiza uma análise da produção do conhecimento sobre comunidades quilombolas no Paraná, especialmente para saber se as práticas corporais são recorrentes nas investigações (SOUZA; LARA, 2011), conquanto o artigo não aprofunde o sentido/significado de práticas corporais quilombolas.

Interessante realçar ainda que, em seu conjunto, observa-se que os 33 trabalhos analisados contam com uma atualização temática no que concerne à maneira de abordar e compreender as populações quilombolas. Até a promulgação da Constituição Federal de 1988, as pesquisas versavam sobre direitos territoriais, jurídicos e políticos dos quilombos e quilombolas. Por outro lado, com o Artigo 68 do Ato das Disposições Constitucionais Transitórias (ADCT) na Constituição Federal de 1988, o conceito de quilombo sofre ressemantizações e ganha novos contornos a fim de contemplar práticas sociais e formações coletivas existentes, que emergem após a valorização e o reposicionamento de uma matriz cultural negra. A autodeclaração quilombola se coloca como um marcador discursivo, mecanismo acionado na memória que reaviva as historicidades e territorialidades construídas por seus ancestrais. Adicionalmente, é preciso salientar que as práticas corporais quilombolas são identificadas em suas potencialidades no tocante à cultura corporal do movimento, em que os corpos quilombolas se autoidentificam e se socializam no/pelo corpo, conforme suas práticas corporais, como, por exemplo, ocorre com o jongo, coco de roda, samba de cacete e com o "Cumê no Mato" (LINS, 2009; MORENO, 2014; CALÚ, 2015; BARRETO, 2017; OLIVEIRA, 2018).

Sobretudo, conforme mencionado anteriormente, o desenvolvimento das pesquisas à luz dessa nova concepção sofreu um impulso nos últimos anos devido ao crescimento do número de programas de pós-graduação no Brasil. Por esta razão, além de analisar o sentido/significado das práticas corporais quilombolas no âmbito da produção acadêmica, buscou-se identificar sua distribuição por área de conhecimento, a partir dos programas de pós-graduação e instituições vinculadas.

Quanto à identificação das áreas de conhecimento que abarcam os trabalhos selecionados, optamos por analisar o conjunto de teses e dissertações formado por 29 itens, ou seja, a maior parte do corpo bibliográfico produzido por meio da busca nas bases de dados. Isso possibilitou o mapeamento das áreas, considerando suas conexões aos programas de pós-graduação. A Tabela 3 nos apresenta um panorama de 16 programas de pós-graduação por onde se distribui o conjunto de teses e dissertações selecionadas. 
Tabela 3 - Quantidade de dissertações e teses por programas de pós-graduação e suas respectivas áreas, no período de 1999 a 2019.

\begin{tabular}{cccc}
\hline Programa de pós-graduação & Dissertação & Tese & Total \\
\hline Educação Física & 4 & 2 & 6 \\
Educação & 2 & 3 & 5 \\
Estudos do Lazer, da Escola de Educação Física, & & 2 \\
Fisioterapia e Terapia Ocupacional & 0 & 2 \\
Antropologia Social & 2 & 0 & 2 \\
Sociologia & 2 & 0 & 2 \\
Ciências em Religião & 2 & 0 & 1 \\
Artes & 1 & 0 & 1 \\
Artes Cênicas & 1 & 0 & 1 \\
Artes Visuais & 1 & 0 & 1 \\
Ciências Sociais & 1 & 0 & 1 \\
Comunicação, Cultura e Cidadania & 1 & 0 & 1 \\
Dança & 1 & 0 & 1 \\
Desenvolvimento e Meio Ambiente & 0 & 1 & 1 \\
Desenvolvimento Sustentável & 1 & 0 & $\mathbf{2 9}$ \\
Educação em Matemática & 1 & 0 & 0 \\
Estudos da Mídia & $\mathbf{2 1}$ & 2 & 2 \\
\hline TOTAL & 1 & 2 & 2 \\
\hline
\end{tabular}

Fonte: elaborado pelos autores, 2020.

Os resultados evidenciam que há uma distribuição do tema por diversas áreas, dada a multiplicidade de possibilidades e a necessidade de aprofundamento de estudos relacionados ao grupo social quilombolas. Os programas de pósgraduação das áreas de Educação Física e Educação se destacam como aqueles que mais desenvolveram pesquisas relacionadas às práticas corporais quilombolas. A Educação Física totaliza seis produções, sendo quatro dissertações e duas teses. Os programas de Educação, por sua vez, totalizam cinco produções, divididas em duas dissertações e três teses. Esse dado é relevante por possibilitar a comprovação de que estudos sobre corpo no Brasil são predominantemente produzidos pela área de Educação Física, como já anteriormente enunciado por Silva et al. (2016) e, nesse sentido, os estudos também apontam que as Ciências Sociais e a Educação Física se enovelam na produção do conhecimento a respeito do corpo, produzindo sentidos e significados localizados socialmente e manifestados na e pela corporeidade.

Procurando avançar no mapeamento, identificaram-se as instituições vinculadas. Conforme discriminado na Tabela 4, 20 instituições apoiaram a realização de pesquisas sobre práticas corporais quilombolas. 
Tabela 4 - Quantidade de dissertações e teses por instituição, no período de 1999-2019.

\begin{tabular}{cccc}
\hline Instituição & Dissertações & Teses & Total \\
\hline UnB & 4 & 1 & 5 \\
UFC & 2 & 1 & 2 \\
UFRN & 2 & 0 & 2 \\
UFMG & 0 & 2 & 2 \\
UFBA & 2 & 0 & 1 \\
UFSE & 0 & 1 & 1 \\
UERJ & 0 & 1 & 1 \\
Unicamp & 0 & 1 & 1 \\
PUC-Rio & 0 & 1 & 1 \\
UNICAP & 1 & 0 & 1 \\
UFPB-UFPE & 1 & 0 & 1 \\
PUCRS & 1 & 0 & 1 \\
UFGO & 1 & 0 & 1 \\
Unesp & 1 & 0 & 1 \\
UFRGS & 1 & 0 & 1 \\
UFJF & 1 & 0 & 1 \\
UFPel & 1 & 0 & 1 \\
Ufes & 1 & 0 & 1 \\
UFSE & 1 & 0 & 1 \\
UFMT & 1 & 0 & 1 \\
Total & 1 & 1 & 1 \\
\hline & 1 & 0 & 1 \\
\hline
\end{tabular}

Fonte: elaborado pelos autores, 2020.

Os dados da Tabela 4 revelam que a Universidade de Brasília (UnB) lidera, em termos de produção sobre práticas corporais quilombolas, com cinco estudos, sendo quatro dissertações de mestrado e uma tese de doutorado, ao longo dos 20 anos considerados. Em seguida se evidencia a Universidade Federal do Ceará (UFC), com três pesquisas, sendo duas dissertações de mestrado e uma tese de doutorado. Também devemos fazer o registro que foi identificado um número maior de dissertações do que teses, posto que temos 21 dissertações e oito teses. O mapeamento geoespacial destas instituições no território brasileiro foi representado na Figura 3, onde se pode constatar a ausência de instituições situadas na Região Norte. 
Figura 3 - Mapa das instituições vinculadas à produção sobre a temática, no período de 1999 a 2019.

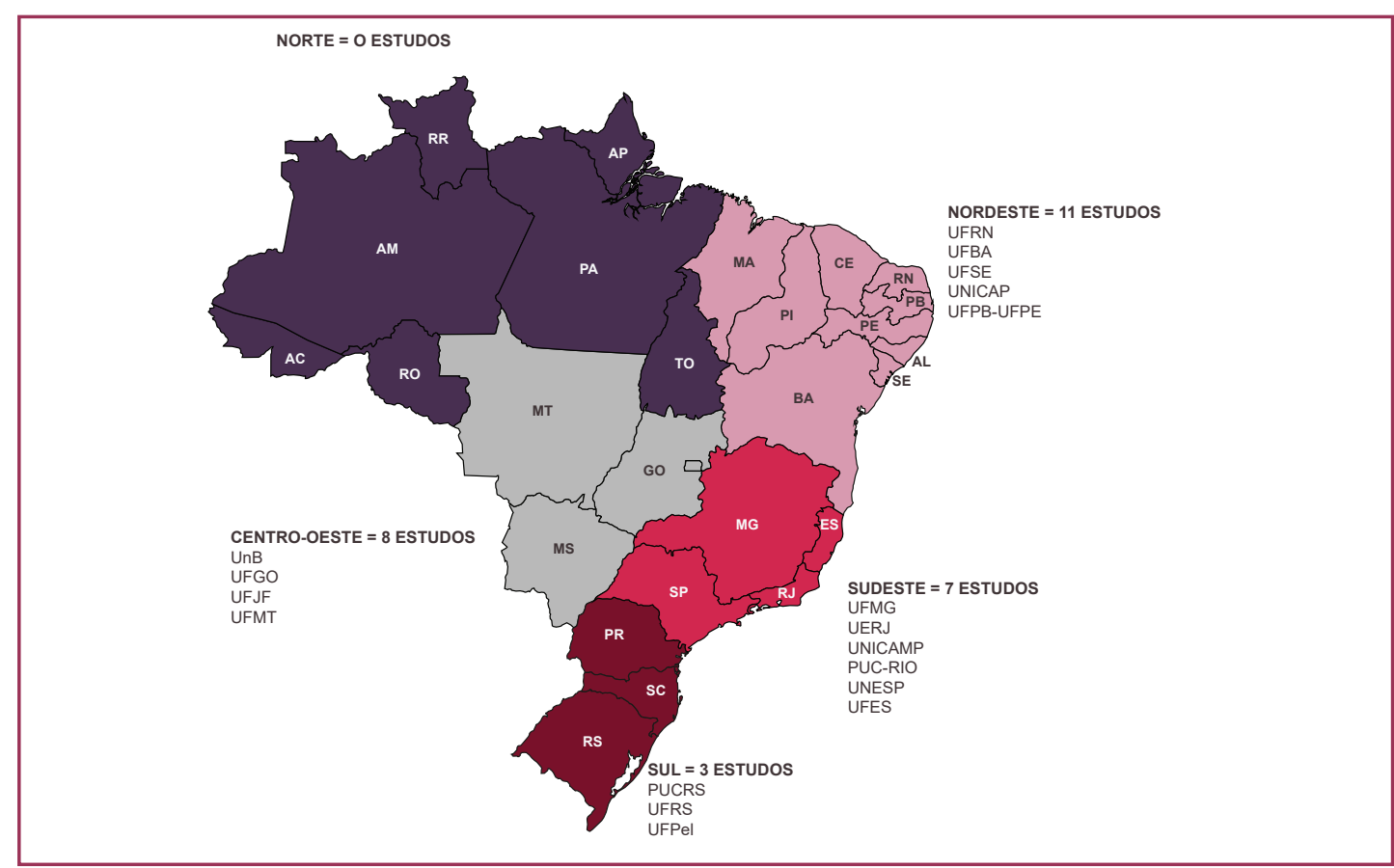

Fonte: elaborado pelos autores, 2020

A fim de completar o mapeamento geoespacial dos trabalhos selecionados, buscamos identificar o lócus das pesquisas de campo. Para isso, voltamos a considerar os 33 produtos selecionados por meio das bases de dados, pois tanto teses e dissertações como artigos nos oferecem essa informação. Observamos que os estudos contemplam comunidades quilombolas de todas as regiões brasileiras, com maior incidência no Nordeste (Figura 4).

Figura 4 - Localidades onde foram desenvolvidas pesquisas na temática práticas corporais quilombolas, no período de 1999 a 2019.

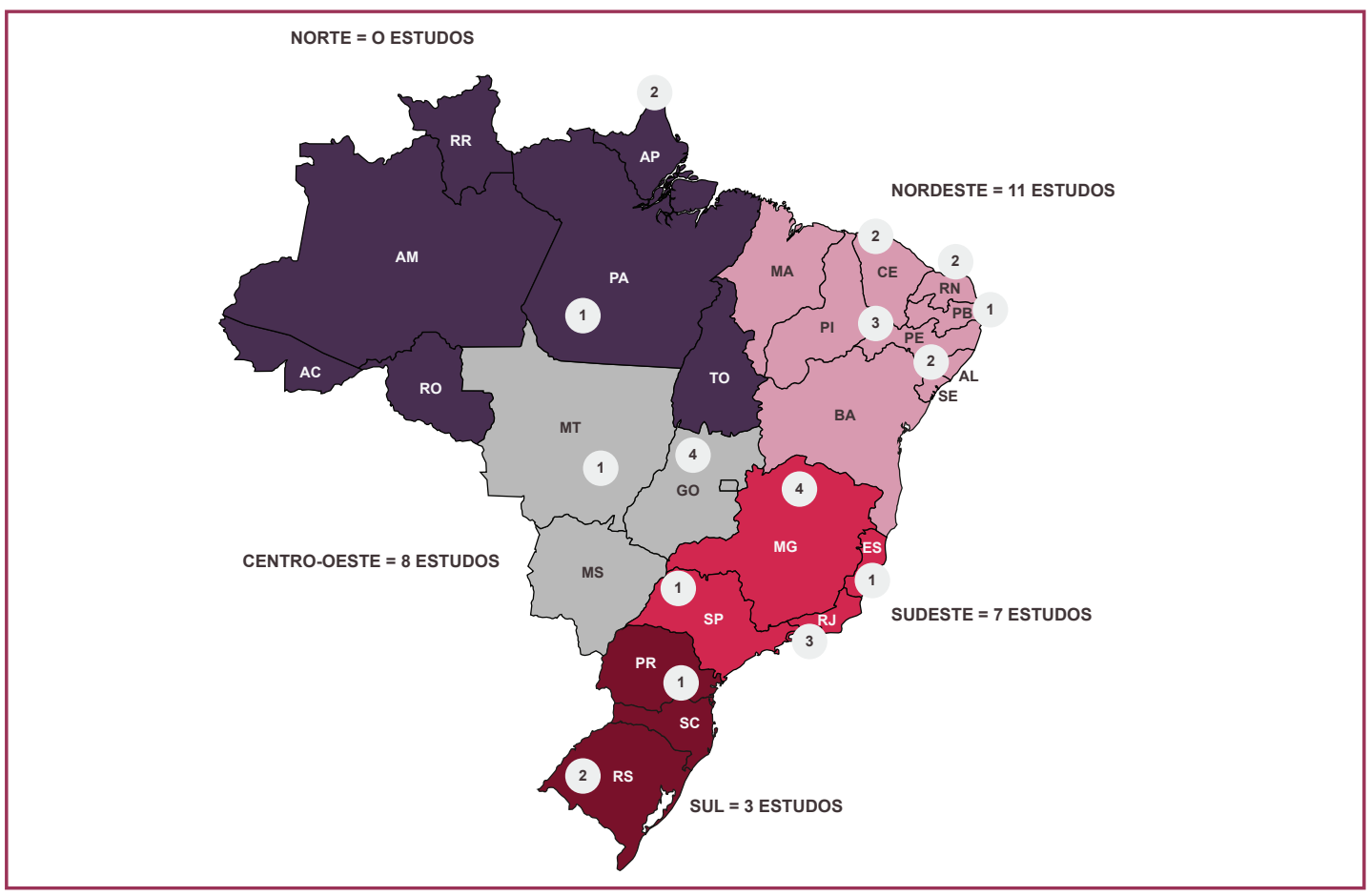

Fonte: elaborado pelos autores, 2020. 
A maioria dos estudos sobre práticas corporais quilombolas, portanto, foi realizada acerca de comunidades localizadas na Região Nordeste do Brasil, sendo três em Pernambuco, duas no Ceará, duas no Rio Grande do Norte, duas em Sergipe e apenas uma no estado da Paraíba, totalizando doze trabalhos.

De acordo com antecipação do Censo de 2021 do Instituto Brasileiro de Geografia e Estatística (IBGE), há 3.171 comunidades quilombolas na Região Nordeste do país, que representa pouco mais da metade do total do território brasileiro, que é de 5.972. Na Região Sudeste, encontram-se 1.359 comunidades. As demais, por sua vez, estão distribuídas entre as regiões Norte (873), Sul (319) e Centro-Oeste (250) (IBGE, 2020). Portanto, o fato de se identificar nos estudos desenvolvidos acerca das práticas corporais quilombolas um maior número de trabalhos que tomam como lócus da investigação comunidades do Nordeste faz sentido, quando cotejamos com dados do IBGE (2020). Não obstante, do ponto de vista proporcional, não é possível inferir qualquer proporcionalidade entre o número de estudos desenvolvidos e o total de comunidades quilombolas presentes no Nordeste brasileiro.

Em adição, quando comparamos o mapa da Figura 3 com o da Figura 4, verificamos que a produção científica sobre práticas corporais quilombolas está distribuída territorialmente, quando se considera numericamente as populações quilombolas, cuja localização preponderante é na Região Nordeste, bem como o lócus das pesquisas de campo, que é igualmente a Região Nordeste. Podemos registrar, por fim, que os estudos realizados acerca das comunidades quilombolas atendem a um critério de distribuição geoespacial, pois identificamos, em toda as regiões, investigações sobre essas comunidades e suas práticas corporais. Todavia, o fato de a maioria da produção em formato de teses e dissertações estar concentrada em instituições localizadas no eixo Centro-Oeste, Sul e Sudeste indica a necessidade de deslocamento dos(as) pesquisadores(as) para desenvolver estudos fora de seu estado e/ou região, como é o caso da Região Norte. Isso denota a necessidade da continuação do processo de interiorização dos programas de pós-graduação, já iniciado nos últimos anos.

\section{CONSIDERAÇÕES FINAIS}

Diante dos objetivos, evidenciou-se que a produção sobre práticas corporais quilombolas, no período compreendido entre 1999 e 2019, concentra-se no conjunto "Representações sociais sobre a cultura corporal de movimento". No âmbito deste conjunto, por sua vez, foi privilegiada a categoria "Práticas corporais e sociedade" e especificamente a subcategoria "Práticas corporais como manifestações culturais". Os estudos dedicados a dança e festividades tradicionais, enfocando processos identitários das comunidades, são predominantes.

Verificou-se que a maior parte da produção está circunscrita ao campo da Educação Física, seguida pela Educação. Existe uma produção concentrada em algumas universidades brasileiras, como a Universidade de Brasília (UnB) e a Universidade Federal do Ceará (UFC). Depreende-se que tal assertiva encontra 
sentido quando se percebe a localização destas instituições no território brasileiro, pois próximo a estas instituições predominam comunidades quilombolas.

A maior parte da produção encontrada está no formato de dissertação. Sobre este aspecto, realça-se que a quantidade de programas de pós-graduação em Educação Física em nível de doutorado é relativamente recente no país. Por outro lado, a maior quantidade de artigos científicos gerados está relacionada a teses, o que nos leva a inferir que talvez a possibilidade de publicação de artigo científico resultante de tese seja concreta. Face aos resultados apresentados, inferimos que há escassez de produções voltadas à temática das práticas corporais quilombolas, dado que reforça pesquisas anteriores realizadas por Almeida et al. (2017). Mas trata-se de um tema emergente, cujo crescimento gradativo, principalmente ao longo dos últimos dez anos, foi evidenciado.

Estudos sobre as práticas corporais em comunidades quilombolas configuramse como um campo inesgotável de pesquisa. Investigações realizadas sobre essa temática podem contribuir para o acervo de práticas corporais dessas populações, considerando a tradição e a construção da identidade nacional. Portanto, estudá-las seria uma forma de chegar à dimensão social das expressões, das manifestações e dos significados corporais, possibilitando a consolidação de um novo entendimento das dinâmicas e relações sociais no cenário das comunidades quilombolas. Notadamente, vale o registro de que não há história e memória construída se não houver estudos e pesquisas sobre ela realizados. A construção da identidade nacional, tanto de brancos, de indígenas, quanto de pardos, pretos ou negros se dá por meio do reconhecimento de nossas raízes. Somente por este âmbito que o sentido/significado de nacionalidade se constituirá.

\section{REFERÊNCIAS}

ALMEIDA, Dulce Maria Filgueira de et al. Atividades físicas e esportivas e populações tradicionais. In: Programa das Nações Unidas (PNUD). Relatório de Desenvolvimento Humano Nacional. Movimento é Vida: Atividades Físicas e Esportivas para Todas as Pessoas. Brasília, 2017. p.40-57.

BARRETO, Janaina Lucene Mendonza. Coco de roda novo quilombo: da roda ao centro, imagens e símbolos de uma tradição. 2017. 103 f. Tese (Doutorado em Artes Visuais) - Programa de Pós-graduação em Artes Visuais, Universidade Federal da Bahia, Universidade Federal de Pernambuco, João Pessoa, 2017.

BEZERRA, Vanessa Moraes et al. Domínios de atividade física em comunidades quilombolas do sudoeste da Bahia, Brasil: estudo de base populacional. Cadernos de Saúde Pública, v.31, n.6, p.1213-1224, jun.2015.

BRASIL. [Constituição (1988)]. Constituição da República Federativa do Brasil: promulgada em 5 de outubro de 1988. Cap. III - Da Educação, Da Cultura e Do Desporto, Art. 215. Disponível em: http://www.jusbrasil.com.br/topicos/10648364/artigo-215-daconstituicao-federal-de-1988 . Acesso em: 30 jan. 2020. 
CALÚ, Carmen Lúcia Barbosa. Corpos no samba de cacete: dança ancestral, tamboros giras e gingas na educação afrocametaense. 2015. 69 f. Dissertação (Mestrado em Educação) - Programa de Pós-Graduação em Educação, Universidade Federal do Ceará, Fortaleza, 2015.

COFFEY, Amanda. Analysing documents. In: FLICK, Uwe. The sage handbook of qualitative data analysis. London: Sage, 2014. p. 367-379.

COSTA, Edymara Diniz. O ensino do teatro em comunidades negras rurais: Memórias e identidades Kalunga em cena. 2015. 151 f. Dissertação (Mestrado em Artes) - Universidade de Brasília, Brasília, DF. 2015.

COSTA, Rute Ramos da Silva; FONSECA, Alexandre Brasil. Análise das práticas pedagógicas o processo educativo do jongo no quilombo machadinha: oralidade, saber da experiência e identidade. Revista Educação e Sociedade, v. 40, e0182040, 2019. DOI: https://doi.org/10.1590/ES0101-73302019182040

FAUSTO, Boris. História do Brasil. 12. ed. São Paulo: EDUSP, 2006.

FLICK, Uwe. Introdução à pesquisa qualitativa. 3. ed. Porto Alegre: Artmed, 2009.

IBGE - INSTITUTO BRASILEIRO DE GEOGRAFIA E ESTATÍSTICA. Base de Informações Geográficas e Estatísticas sobre os Indígenas e Quilombolas: Censo Demográfico 2020. Disponível em: http://www.ibge.gov.br/geociencias/organizacao-do-territorio/tipologiasdo-territorio/27480-base-de-informacoes-sobre-os-povos-indigenas-e-quilombolas. html?=\&t=o-que-e. Acesso em: 30 jun. 2020.

LACERDA, Roberto Santos. Territorialidade, Saúde e Meio Ambiente: Conexões, Saberes e Práticas em Comunidades Quilombolas de Sergipe. 2017. 248f. Tese (Doutorado em Desenvolvimento e Meio Ambiente) - Universidade Federal de Sergipe, São Cristóvão, 2017.

LE BRETON, David. A sociologia do corpo. 6. ed. Petrópolis: Vozes. 2006.

LIMA, Isabela Talita Gonçalves; BRASILEIRO, Lívia Tenório. A cultura afro-brasileira e a educação física: um retrato da produção do conhecimento. Movimento (Porto Alegre), v. 26, e26022, 2020. DOI: https://doi.org/10.22456/1982-8918.93164

LINS, Cyro Holando de Almeida. O Zambê é nossa cultura: o coco de zambê e a emergência ética em Sibaúma, Tibau do Sul-RN. 2009. 108 f. Dissertação (Mestrado Antropologia Social) - Universidade Federal do Rio Grande do Norte, Natal, 2009.

LUNA, Sergio Vasconcelos de. Planejamento de pesquisa: uma introdução. São Paulo: Educ., 1997.

MAROUN, Kalyla. A construção de uma identidade quilombola a partir da prática corporal/ cultural do jongo. Movimento, v. 20, n.01, p.13-31, jan/mar. 2014. DOI: https://doi. org/10.22456/1982-8918.39882

MAROUN, Kalyla. Jongo e educação: a construção de uma identidade quilombola a partir de saberes étnico-culturais do corpo. 2013. 210 f. Tese (Doutorado em Educação) Pontifícia Universidade Católica do Rio de Janeiro, Rio de Janeiro, 2013.

MAUSS, Marcel. Sociologia e Antropologia. São Paulo: Ubu Editora, 2017.

MORENO, Daniele Cristiane Gadelha. Os quilombolas do Veiga e o São Gonçalo: memória e identidade na festa e devoção a São Gonçalo no sítio Veiga. 2014. 199f.

Dissertação (Mestrado em Sociologia) - Centro de Humanidades, Universidade Federal do Ceará, Fortaleza, 2014. 
OLIVEIRA, Ana Amélia Neri. Entre o Rio e o Mar: práticas corporais e cotidiano na comunidade quilombola do Cumbe. 2018. 181 f. Tese (Doutorado em Educação Física) Faculdade de Educação Física, Universidade de Brasília-UnB, Brasília, 2018.

PEREIRA, Milena Cassal. Brincando de sair pra rua! Entre arreganhos, implicâncias e cuidados no "pátio" do quilombo, na "piscina" do laguinho. 2014. 140 f. Dissertação (Mestrado em Ciências Sociais) - Pontifícia Universidade Católica do Rio Grande do Sul, Porto Alegre, 2014.

PNUD - PROGRAMA DAS NAÇÕES UNIDAS. Relatório de Desenvolvimento Humano Nacional. Movimento é Vida: atividades físicas e esportivas para todas as pessoas. Brasília, DF: PNUD, 2017.

RAMOS, Plínio dos Santos et al. Dissertações e teses de pós-graduação geram publicação de artigos científicos? Análise baseada em 3 programas da área de educação física.

Brazilian Journal of Biomotricity, v.3, n.4, p.315-324, 2009.

RAPLEY, Tim; REES, Gethin. Colecting documents as data. In: FLICK, Uwe. The sage handbook of qualitative data analysis. London: Sage, 2018. p. 378-391.

RIO GRANDE DO SUL. Secretaria de Estado da Educação. Departamento Pedagógico. Referenciais Curriculares do Estado do Rio Grande do Sul - Lições do Rio Grande: Linguagens, Códigos e suas Tecnologias - Arte e Educação Física - 130 Caderno do Professor. Porto Alegre: Secretaria de Estado da Educação do Rio Grande do Sul, 2009. v. 2. p.110-184.

SANTOS, Marcos Paulo de Oliveira. As Representações Sociais das Práticas Corporais na Comunidade Kalunga-Go. 2011. 111 f. Dissertação (Mestrado em Educação Física) Faculdade de Educação Física, Universidade de Brasília, Brasília, DF, 2011.

SCHMITT, Alessandra; TURATTI, Maria Cecília Manzoli; CARVALHO, Maria Celina Pereira de. A Atualização do conceito de quilombo: identidade e território nas definições teóricas.

Ambiente \& Sociedade, n. 10, p. 1-10, 2002.

SILVA, Andréa Oliveira Araújo da. A gira de saberes no processo de criação de ESTELLA: Manifesto por uma Dança Afropoética. 2018. 141 f. Dissertação (Mestrado em Dança) - Universidade Federal da Bahia, Salvador, 2018.

SILVA, Thais Queiroz; ALMEIDA, Dulce; WIGGERS, Ingrid; ANDREWS, David; SILVA, Letícia Rodrigues T. Is there a sociology of the body in Brazil? Movimento, v.22, n.4, p.1249-1264, out./dez. 2016. DOI: https://doi.org/10.22456/1982-8918.61981

SOUZA, Thaís Godoi de; LARA, Larissa Michelle. O estado da arte de comunidades quilombolas no Paraná: produção de conhecimento e práticas corporais recorrentes. Revista de Educação Física/UEM, v.22, n.4, p.555-568, dez. 2011. 
Abstract: The paper analyzes the sense/meaning of quilombola bodily practices in academic production, identifying their distribution by areas of knowledge and their geospatial mapping in Brazil. Theoretical and bibliographic research was carried out in databases from 1999 to 2019. The results point out that the sense/meaning of bodily practices is associated with social representations about the body culture of movement, showing that Physical Education and Education stand out among the areas of knowledge, and studies are geospatially distributed in Brazil. Research loci are predominantly in the Northeast region, whereas the University of Brasilia and the Federal University of Ceará stand out in numbers of studies. The conclusion is that, while the topic is recent and studies are scarce, its relevance encourages a research agenda.

Keywords: Exercise. African continental ancestry group. Scientific publication indicators. Physical Education.

Resumen: El artículo analiza el sentido/significado de las prácticas corporales quilombolas en la producción académica, identificando su distribución por áreas de conocimiento y su mapeo geoespacial en Brasil. Se realizó una investigación de carácter teórico y bibliográfico en bases de datos, en el período comprendido entre 1999 y 2019. Los resultados muestran que el sentido/significado de las prácticas corporales está asociado con las representaciones sociales sobre la cultura corporal de movimiento, mostrando que la Educación Física y la Educación destacan entre las áreas de conocimiento y los estudios se distribuyen geoespacialmente en Brasil. Los loci de las investigaciones se encuentran, predominantemente, en la región Nordeste y la Universidad de Brasilia y la Universidad Federal de Ceará destacan en número de trabajos. Se concluye que, a pesar de reciente y poco estudiada, la relevancia del tema estimula una agenda de investigación.

Palabras clave: Ejercicio físico. Grupo con ancestrales en el continente africano. Indicadores de producción científica. Educación Física. 


\section{LICENÇA DE USO}

Este é um artigo publicado em acesso aberto (Open Access) sob a licença Creative Commons Atribuição 4.0 Internacional (CC BY 4.0), que permite uso, distribuição e reprodução em qualquer meio, desde que o trabalho original seja corretamente citado. Mais informações em: https://creativecommons.org/licenses/by/4.0

\section{CONFLITO DE INTERESSES}

Os autores declararam que não existe nenhum conflito de interesses neste trabalho.

\section{CONTRIBUIÇÕES AUTORAIS}

Paulino Pinheiro Gaia: Conceituação, curadoria de dados, análise formal, metodologia de investigação, visualização, escrita, redação do rascunho original, revisão, edição.

Layana Costa Ribeiro Cardoso: Conceituação, análise formal, visualização, escrita.

Maria Denise Dourado da Silva: Conceituação, análise formal, metodologia de investigação, visualização, escrita, edição.

Ingrid Dittrich Wiggers: Análise formal, metodologia de investigação, visualização, revisão, edição.

Dulce Maria Filgueira de Almeida: Análise formal, redação do rascunho original, revisão, edição.

\section{FINANCIAMENTO}

O presente trabalho foi realizado sem o apoio de fontes financiadoras.

\section{COMO REFERENCIAR}

GAIA, Paulino Pinheiro; WIGGERS, Ingrid Dittrich; CARDOSO, Layana Costa Ribeiro; SILVA, Maria Denise Dourado da; ALMEIDA, Dulce Maria Filgueira de. Práticas corporais quilombolas: um estudo da produção acadêmica na educação física. Movimento (Porto Alegre), v.27, p.e27054, jan./dez. 2021. Disponível em: https://seer.ufrgs.br/Movimento/article/view/111523. Acesso em: [dia] [mês abreviado]. [ano]. DOI: https://doi.org/10.22456/1982-8918.111523

\section{RESPONSABILIDADE EDITORIAL}

Alex Branco Fraga*, Elisandro Schultz Wittizorecki*, Ivone Job*, Mauro Myskiw*, Raquel da Silveira*

*Universidade Federal do Rio Grande do Sul, Escola de Educação Física, Fisioterapia e Dança, Porto Alegre, RS, Brasil. 